\title{
O SIONISMO E A LITERATURA DE YOSEF HAIM BRENNER: UMA HISTÓRIA DE AMBIVALENCIAS
}

\section{ZIONISM AND LITERATURE OF YOSEF HAIM BRENNER: A HISTORY OF AMBIVALENCES}

Luis Krausz ${ }^{*}$

\begin{abstract}
Resumo
Este artigo discute as ambivalências do escritor Yosef Haim Brenner em suas representações do projeto ideológico do sionismo. Militante de uma literatura desvinculada de qualquer viés político, passível de ser instrumentalizada por uma ideologia hegemônica, Brenner propõe no romance Shekhol ve Kishalon um retrato pouco edificante da vida no Kibutz e, ao mesmo tempo, faz uma representação crítica dos modos de vida e de pensamento típicos da Diáspora, que continuam influenciando a vida de um grupo de imigrantes radicado em Jerusalém. Seu niilismo, em que se mostra uma clara influência de Dostoiévski, emerge no olhar crítico com que contempla a sociedade judaica, dentro e fora da Terra de Israel.
\end{abstract}

Palavras-chave: Literatura Hebraica, Y. H. Brenner, Sionismo, Diáspora.

\begin{abstract}
This article discusses Yosef Haim Brenner's ambivalence in his literary renderings of Zionism's ideological project. Advocating a literature disengaged from any kind of political bias, which could serve the interest of an hegemonic ideology, Brenner offers the reader in his novel Shekhol ve Kishalon a dark picture of life in the Kibutz and, at the same time, also makes critical renderings of the ways of life and ways of thought typical of the Diaspora, which continue to influence the life of a group of immigrants in Jerusalem. His Nihilism, a clear influence from Dostoyevsky, emerges from his critical outlook on Jewish life inside and outside of Israel.
\end{abstract}

\footnotetext{
* Professor de Literatura Hebraica na Universidade de São Paulo.
} 
Keywords: Hebrew Literature, Y. H. Brenner, Zionism, Diaspora. 
Yosef Haim Brenner (1881-1921) influenciou de maneira decisiva a geração de imigrantes, sobretudo de origem russa, que se estabeleceu na Palestina Otomana entre os anos de 1904 e 1914, na chamada $2^{\mathrm{a}}$ Aliá. Esses imigrantes, imbuídos de ideais socialistas, trabalhistas e nacionalistas, foram os responsáveis pela criação da ideologia que viria a se tornar hegemônica nas primeiras décadas de existência do Estado de Israel - uma ideologia de caráter secular, libertário, que insistia na necessidade de ruptura com o passado diaspórico do povo judeu e que via no projeto sionista de assentamento nas terras da promissão bíblica o caminho para a autorredenção judaica.

Brenner foi seguidor entusiasmado das doutrinas de Aaron David Gordon (1856-1922), ideólogo do sionismo trabalhista e do renascimento nacional e espiritual judaico, fundador do movimento Hapoel Hatzair (O Jovem Trabalhador), que congregava na Palestina a vanguarda ideológica da $2^{\mathrm{a}}$ Aliá. Marcado pelas ideias de Leon Tolstói, assim como pelo hassidismo, Gordon fez do trabalho, especialmente o agrícola, e da vida simples junto à natureza uma espécie de nova religião, que teve importância decisiva na criação do embrião do Estado de Israel nas primeiras décadas do século XX, bem como na formação do movimento kibutziano. Afirmou que a causa do sofrimento dos judeus na Diáspora decorria de sua posição parasitária nas sociedades, e considerava o trabalho agrícola como cura para as anomalias acumuladas por dois mil anos de exílio judaico:

O povo judeu foi completamente amputado da natureza e aprisionado nas paredes das cidades por dois mil anos. Nós nos acostumamos a todos os tipos de vida, exceto à vida do trabalho - o trabalho feito em nosso benefício, e por seu próprio valor. Será preciso o mais intenso esforço da vontade para que um povo assim possa voltar à normalidade. Falta-nos o ingrediente principal para uma vida nacional: falta-nos o hábito do trabalho... (GORDON apud SUFIAN, 2007, p. 33).

Brenner incorporou as premissas de Gordon em sua obra literária, que se caracteriza por formular críticas implacáveis às formas de vida do judaísmo diaspórico, o qual invariavelmente retrata por um prisma negativo. Entretanto, sempre se absteve de fazer de seus contos e romances meras apologias aos ideais do sionismo trabalhista. Avesso a uma literatura nos moldes de um realismo socialista, criadora de mitos e de heróis a serem emulados na realidade como forma de melhorar e transformar a sociedade, Brenner insistia na necessidade de transformação do povo 
judeu, mas tinha dúvidas a respeito da viabilidade do assentamento judaico na Palestina, tanto no âmbito pessoal quanto no coletivo. Embora tenha vivido ali durante os últimos doze anos de sua vida, também tinha suspeitas com relação à retórica nacionalista em torno da criação de um "novo homem hebreu", e nesse sentido opôs-se diametralmente à chamada "literatura do gênero eretz-isralense", que em seu tempo ganhava espaço na Palestina, mas lhe parecia tendenciosa e excessivamente devotada aos modelos artísticos importados de um romantismo tardio.

Há, portanto, uma ambivalência intrínseca na apreciação do sionismo na obra de Brenner, já que a glorificação dos ideais desse movimento nacionalista, aos quais ele subscrevia, era, no seu entender, incompatível com um fazer literário legítimo. Sua relação com o fervor ideológico em torno do assentamento judaico na Palestina é marcada por uma grande complexidade, na qual as tendências irreconciliáveis do desdém para com os escritores que aderem sem questionamentos aos dogmas sionistas - autores que eram seus contemporâneos e que denominava "escritores do gênero", como Moshe Smilansky, Yosef Luidor e Meir Wilkansky - e sua admiração por esses mesmos dogmas coexistem com uma devoção inquestionável à autenticidade literária.

Os "escritores do gênero" forjaram, em contos e romances, heróis destinados a simbolizar, com um propósito didático, o "novo homem hebreu" concebido pelos diferentes ideólogos do sionismo - de Ahad Ha'Am e Aaron David Gordon a Theodor Herzl e Max Nordau. Representantes de uma literatura engajada no propósito de apresentar aos leitores paradigmas positivos de pensamento e de comportamento, foram criticados por Brenner num ensaio devastador, intitulado O Gênero Eretz-israelense e seus Artefatos, publicado em $1911^{1}$.

Para Brenner, o propósito dessa literatura estava fadado ao fracasso porque seus expoentes, em vez de insistir sobre a necessidade de uma transformação íntima dos judeus, tendiam a deslumbrar-se com uma retórica grandiloquente, para a qual não havia a necessária contrapartida de ação real. A regressão dos judeus na Palestina aos modos de vida da Diáspora é o fantasma para o qual Brenner sempre volta a apontar em suas obras literárias escritas em seu período palestino, conforme afirma Dan Miron:

\footnotetext{
${ }^{1}$ O "hebreu novo" e o "eretz-israelense novo" são modelos literários que povoam os romances e contos escritos em hebraico na Europa do século XIX assim como na Palestina das primeiras décadas do século XX. Segundo EvenZohar (1998), “o 'eretz-israelense' tende a ser a concretização 'completa' do modelo, enquanto o 'hebreu', na maioria das vezes, é mesclado a modelos 'do exílio', mas já no nível do modelo. Apesar da grande semelhança entre os dois modelos, como se pode abstrair dos diversos contos, ainda assim há importantes diferenças entre eles”.
} 
Brenner criticou acerbamente o que ele rotulou como o "gênero palestino", a ficção em prosa escrita na Palestina por aqueles que atribuíam à simples presença dos judeus em seu antigo lar nacional uma qualidade redentora que se afirmava em sua apresentação da realidade pelo prisma da idealização. [...] Ele mesmo não considerava que o contingente judaico na Palestina - aí incluída sua parcela secular-sionista - tivesse qualquer diferença com qualquer outro agregado de imigrantes judeus em qualquer outra parte do mundo (América do Norte, o bairro londrino de Whitechapel, a Argentina ou a África do Sul) com exceção daqueles poucos dentre seus membros que faziam uma tentativa séria de romper com as características essenciais da vida judaica no exílio, que consistia em ocupar a posição de intermediários, de mediadores, comerciais ou intelectuais, entre os que fazem o "trabalho primordial da vida" (i.e., satisfazem as necessidades humanas básicas) e os que consomem os produtos do trabalho duro dos primeiros (MIRON, 2010, p. 118).

Brenner escreveu sobre a existência judaica na Diáspora assim como sobre as tentativas dos judeus de fincarem raízes nas antigas terras de Israel, mas o tom de sua literatura jamais é otimista e nunca cede à tentação de representar o assentamento judaico na Palestina como um universo róseo e povoado de heróis. Acredita na escrita como um instrumento de transformação social, mas pela via inversa daquela escolhida pelos "escritores do gênero". À maneira de Scholem Abramowitch (mais conhecido como Mendele Moicher Sforim) (1835-1917), o fundador da moderna literatura iídiche, cuja obra é, sobretudo, uma denúncia do vazio, da hipocrisia e das falsidades sobre as quais se constrói o universo decrépito do shtetl Leste-europeu, Brenner acredita que a ficção, por meio de sua capacidade de chocar e de revoltar, pode levar o leitor a uma tomada de consciência que poderá desencadear as necessárias transformações na realidade social.

Ele foi também um opositor ferrenho da ideia da arte pele arte - o que o levou a sérios desentendimentos com seu contemporâneo e amigo Uri Nisan Gnessin (1879-1913) - e alguém que defendeu a necessidade de engajamento dos literatos num processo de transformação e aperfeiçoamento das mentalidades. Foi um escritor comprometido com uma agenda sionista, mas cujos métodos foram, sempre, a denúncia, a exposição do grotesco, a provocação - nunca a apologia.

A meio caminho entre a artificialidade de uma arte plenamente comprometida com a difusão ideológica e a frivolidade de uma arte que se esgota em si mesma, ele considerava a 
literatura como instrumento de esclarecimento e de criação de consciência, numa visão condizente com o ideário da Haskalá, que o influenciaria já desde a adolescência. A ideia do escritor como representação da consciência de sua geração, assim, era-lhe cara.

Em sua breve existência, Brenner viveu, na própria carne, as agonias de uma era de transição para o povo judeu, entre o crepúsculo do shtetl e as promessas de salvação ainda não realizadas - na Palestina assim como no Ocidente. Retratar a decadência e a destruição de um mundo cujos valores perderam o significado, assim, tornou-se parte obrigatória de seu projeto literário.

Descrente e afastado da religião, Brenner criou personagens que se empenham em chegar a termos com uma vida sem Deus - consoante suas filiações sucessivas ao marxismo e, posteriormente, ao sionismo. Segundo David Patterson (apud BRENNER, 2008, p. 6), "Brenner era a corporificação do paradoxo de que a esperança brota do desespero, de que o otimismo provém do pessimismo, e de que frequentemente é preciso ser cruel para ser bondoso". Em sua obra, os judeus da dispersão são examinados e condenados como um compósito de "hipocrisia e vergonha, que têm uma vida pela metade, desprovida de propósito e inefetiva" (Idem, p. 11). Mas Brenner é cáustico com a piedade tradicional do Leste europeu e com o Iluminismo ocidental, que no seu entender conduzia ao assimilacionismo. Essas duas tendências conflitantes do judaísmo europeu deveriam, em sua opinião, ceder espaço para a doutrina sionista, fundamentada no propósito de regeneração nacional e no princípio de responsabilidade individual.

Segundo o crítico e historiador de literatura Joseph Klausner, Brenner

\begin{abstract}
via a vida judaica em todas as suas ramificações e estratos sociais como uma grande bacia de mal. Em seus romances extensos, No Inverno (1903) e Em torno do ponto (1904); em seu profundo drama Além das Fronteiras (1907) e em seus numerosos contos ele retrata a vida miserável e desesperançada de um povo a quem falta uma fundação territorial independente ou um fundamento espiritual uma vida que não é senão uma longa série de anomalias e de sofrimentos e de dores sem propósito e sem fim. A pobreza e a melancolia do "bairro judeu", especialmente em meio às classes mais pobres, leva Brenner a um zênite de tristeza e de desânimo que o preenchem de desespero: ele é incapaz de ver um objetivo ou uma saída (KLAUSNER, 1974, p. 186).
\end{abstract}

Seu pessimismo recai sobre todas as diferentes facções judaicas que surgiram na Rússia do fim do século XIX em decorrência do esgotamento das formas de vida judaicas tradicionais bem 
como da violência antijudaica patrocinada pelo Estado. Se ele se sente revoltado com a classe dos judeus semieducados pelo estudo do Talmude no Cheder e na Yeshivá, que "entupiram suas jovens mentes com a velha casuística dos eruditos e se veem privados de qualquer sentido de realidade" (KLAUSNER, 1974, p. 187), os radicais e socialistas de "origem judaica", que não têm mais nenhum interesse em qualquer coisa judaica, não lhe parecem menos repelentes, pois "também entupiram suas mentes com casuísmos acadêmicos, sendo a única diferença o fato de que suas abstrações são totalmente estranhas ao judaísmo, uma vez que foram importadas de fora e não têm qualquer base na vida nacional judaica" (Ibidem).

De uma maneira geral, sua ira volta-se sobre todos aqueles que reduziram suas ações à verborragia - inclusive os formuladores dos discursos sionistas para quem "a grande ideia do renascimento tornou-se um mero assunto para discursos sem sentido e para a retórica vazia" (Ibidem) A realização desses ideais dependia diretamente do abandono de todas as características judaicas trazidas da Diáspora, que deveriam ser arrancadas do novo solo. Segundo Gershon Shaked,

para a maior parte dos escritores do primeiro período de florescimento da literatura hebraica em Eretz Israel, a experiência dos pioneiros representava uma forma de redenção religiosa, que eles se viam na obrigação de glorificar em seus escritos. Mais do que espelhar a realidade, esses autores desdenhados por Brenner expressavam um entusiasmo ingênuo. A maior parte deles, porém, ignorava as condições objetivas do mundo em que viviam, criando, em seu lugar, uma espécie de país de sonho (SHAKED, 2000, p. 65).

Nos "escritores do gênero", como Moshe Smilansky, Yosef Luidor e Meir Wilkansky, Brenner identificou a mesma tendência ao escapismo que lhe parecia responsável pelos males da Diáspora, e a mesma fascinação pelas ideias que os levariam a produzir uma literatura que não apenas afirmava os valores e os ideais dos pioneiros do sionismo, mas também inventava esses ideais. Ainda, segundo Shaked, "estes escritores foram tão persuasivos que acabaram por influenciar a vida real muito mais do que foram influenciados por ela" (SHAKED, 2000, p. 65). A ficção de Brenner, no entanto, toma uma vertente oposta à da ideologização e da idealização. A vida e a compreensão da literatura como um universo com regras autônomas eram, para ele, mais importantes do que qualquer conjunto de suposições ideológicas - ainda que fossem defensáveis e legítimas a seus olhos. 
Brenner retrata o triunfo de uma visão de mundo corrupta, associada à trágica experiência judaica na Diáspora que frustra os ideais da halutziut. Segundo Shimon Halkin (1950, p. 108), “em muitos sentidos a expressão literária na terra de Israel é uma continuação direta da literatura hebraica moderna que, por décadas a fio, refletiu as vicissitudes da psicologia judaica em sua luta consigo mesma". Seu profundo pessimismo, portanto, tem por alvo uma tendência que ele identificava tanto entre os sionistas espirituais, seguidores de Ahad Ha'Am, quanto entre os sionistas políticos, da linha de Herzl, de se embriagarem com os sonhos fantásticos de salvação quase milagrosa do povo judeu, quando na verdade o sionismo exigia um processo dolorosamente lento de retorno à terra, uma difícil metamorfose de quem retorna do exílio a partir da qual emergiria um novo tipo de judeu, o halutz, isto é, o pioneiro. Na psicologia da Diáspora, segundo Dan Miron, Brenner não identificava qualquer elemento positivo:

Ele não via nada de elevado ou de inspirador na história do exílio judaico, e tampouco tinha admiração pelo antigo hebraísmo bíblico pré-exílico. Ele escandalizou a intelligentsia judaica e hebraica ao afirmar que já era tempo de dispersar a "hipnose" bíblica. Ele claramente não atribuía muito valor intelectual ao Talmude ou ao Midrash (MIRON, 2010, p. 116).

Se Brenner via a si mesmo como um expoente da tradição literária da Haskalá, nem por isso compartilhava das bases intelectuais da literatura do Iluminismo - o racionalismo, a fé no progresso, a capacidade ilimitada de melhoria da condição humana por meio da educação e da racionalização do comportamento do indivíduo e do grupo. Filosoficamente, era um existencialista pessimista que considerava o sofrimento e os conflitos internos como características inalteráveis da condição humana. Robert Alter (1975, p. 141) vê em Brenner "uma das figuras mais atormentadas do universo da literatura hebraica", cujos romances, contos e ensaios se aproximam da intensidade atormentada de Dostoiévski, autor que ele traduziu para o hebraico. Porém, como Alter destaca, não há neles a crença de Dostoiévski no poder salvador da graça. Efetivamente, Brenner foi marcado pelos modelos da literatura russa anti-heroica do fim do século XIX e do início do século XX, assim como pelos modelos consagrados pelo realismo e pelo naturalismo europeus. Aproximou-se, também, do ideário positivista, que ganhava espaço nos guetos e aldeias do Leste da Europa depois de triunfar na França do fim do século XIX, 
segundo o qual a literatura e a arte moderna haviam se tornado meios para se alcançar o objetivo de iluminar a sociedade.

Brenner nasceu de uma família religiosa na aldeia ucraniana de Novi Milni no fatídico ano de 1881, o mesmo ano em que tiveram início os pogroms que marcaram, na Rússia, a passagem do século XIX para o XX. Sua vida foi prematuramente ceifada na insurreição árabe, perto de Jaffa, em 1921, quando foi assassinado pelos participantes do funeral de um jovem árabe morto no conflito.

Estudou em Yeshivot, mas, já no início da adolescência, ligou-se aos seguidores da Haskalá. A influência do clássico de Graetz, História dos Judeus, que Brenner leu em tradução hebraica, foi decisiva para sua atitude de rejeição à tradição hassídica de sua casa paterna, assim como para seu comprometimento com o nacionalismo judaico, que lhe parecia capaz de promover o ressurgimento de seu povo.

Após a ruptura com a tradição e a crença religiosa, Brenner tornou-se, também, seguidor do sionismo espiritual de Ahad Ha'Am, que não pregava o imediato retorno das massas judaicas às terras de seus ancestrais bíblicos, mas sim a transformação dos judeus e a criação de um centro espiritual judaico na Palestina. A intensificação das perseguições aos judeus russos, porém, levou-o a questionar a tese de que os problemas culturais dos judeus tinham precedência sobre os problemas sociais e econômicos enfrentados pelas massas judaicas. "De que forma um "centro judaico' poderia reagir aos terríveis problemas de nosso tempo - reagir não apenas com palavras, mas com atos firmes?" (BRENNER, 2008, p. 33), perguntava-se Brenner ante a tragédia recorrente dos pogroms.

Sua própria experiência de vida - inclusive no serviço militar russo, ao qual foi incorporado em 1901 e do qual desertou em 1904 - comprovou a impossibilidade de qualquer outra solução para os problemas dos judeus russos. Um trecho de um artigo intitulado "Dapim" (páginas), que Brenner publicou em Hameorer, o jornal sionista que ajudou a fundar em Londres, ilustra sua convicção ideológica:

Vejam, os dias estão para chegar - e o lugar para onde temos que ir será nosso. Todos os heróis fracos que hoje derramam em vão seu próprio sangue pela honra de suas irmãs e pela vida de suas mães irão para lá, em meio a cânticos, e começarão a trabalhar (BRENNER, 2008, p. 65). 
O sionismo político, conforme formulado por Theodor Herzl e discutido nos congressos sionistas de 1898 a 1921, realizados em cidades como a Basiléia, Londres, Haia, Karlsbad e Hamburgo, tornou-se então, em sua opinião, a única solução plausível para a terrível realidade judaica do Leste europeu, numa modalidade de ideologia que combinava as ideias de Ahad Ha'Am com o realismo política do sionismo de Herzl.

Brenner chegou à Palestina em 1909, após um período de cerca de quatro anos na Inglaterra, e logo se tornou uma das figuras de proa dentre os membros da $2^{a}$ Aliá. Seu antigo sonho de criar uma comunidade agrícola, conforme as ideias de Tolstói e o ideal reinante do sionismo trabalhista de autossuficiência econômica, o levou ao campo logo após sua chegada, conforme o exemplo de Gordon. Porém, rapidamente ele se dá conta de que esse tipo de vida não lhe servia. Em 1910, estabeleceu-se em Jerusalém e passou a trabalhar como editor em diferentes publicações. Seus colegas, escritores de língua hebraica na Palestina, o consideravam sua "consciência literária"; como o homem que transforma a experiência da vida em experiência das letras.

David Patterson (apud BRENNER, 2008, p. 5) aponta que os pogroms de 1881 foram os desencadeantes de um rápido processo de desmantelamento da cultura e das formas de vida tradicionais dos judeus na região do assentamento judaico na Rússia, e que três vias principais constituíram-se como rotas de fuga ideológica e física para os habitantes do shtetl: em primeiro lugar, a adesão aos movimentos revolucionários, que refletia o fim das esperanças dos judeus de conquistarem uma emancipação pacífica na Rússia czarista; em segundo lugar, a emigração em direção à Europa Ocidental e às Américas, movimento do qual participaram cerca de dois milhões de judeus russos; em terceiro lugar, o advento do Sionismo, que gerou um pequeno porém constante fluxo migratório em direção ao que era, então, a Palestina otomana, onde os judeus recém-chegados começaram a estabelecer os assentamentos agrícolas que se tornariam a base do chamado novo yishuv.

Brenner trilhou todas essas vias de êxodo em sua juventude: foi um revolucionário que hesitou entre o bolchevismo e o socialismo judaico do Bund; foi, também, um emigrante que viveu por quatro anos no gueto londrino de Whitechapel; e foi, finalmente, um pioneiro do sionismo que se estabeleceu na Palestina otomana. Nesse sentido, sua literatura, fundamentada 
em sua própria experiência, é um espelho abrangente dos dilemas e perplexidades dos judeus do Leste da Europa, na passagem do século XIX para o século XX.

Logo de sua chegada à Palestina, Brenner começou a trabalhar no romance Shekhol ve Kishalon (Desolação e Fracasso), considerado como sua obra mais importante que, no entanto, só seria publicada em 1920. Para Baruch Kurzweill (apud WISSE, 2000, p. 90), Desolação e Fracasso é a contrapartida hebraica de O Processo, de Kafka. Terrível porque destrói as esperanças sionistas de um novo início na história judaica, e tem o mesmo tom resignado e desesperançado de $O$ Processo, impregnado da memória histórica que, segundo a ideologia do sionismo, deveria ser obliterada.

O protagonista do romance é Yehezkel Hefetz, um trabalhador agrícola e membro de uma comunidade de pioneiros que sofre um ferimento na virilha enquanto trabalha. Hefetz corresponde, no romance, aos pioneiros que estão no centro da literatura do gênero eretzisraelense. Sua trajetória, porém, em vez de seguir os enredos heroicos que caracterizam esse gênero, movimenta-se em direção à tragédia: o colapso que Hefetz sofre o retira do ambiente dos agricultores para conduzi-lo a Jerusalém, onde, incapaz de se recompor e de adquirir as forças necessárias para retornar ao campo, permanece na casa de seu tio Yosef em companhia das duas primas, Esther e Miriam, e do irmão de seu tio, Haim.

É a partir deste incidente que o foco da narrativa volta-se sobre o yishuv judaico da Jerusalém otomana, uma sociedade corrupta e decadente que tem como principal fonte de sustento a chamada chaluká, uma série de instituições de benemerência dependentes de comunidades judaicas da Diáspora, que sustentam seus egressos em Jerusalém. Segundo Tom Segev (2000, p. 69), sob o domínio otomano "a maior parte dos judeus de Jerusalém sempre viveu dos donativos das comunidades judaicas na Europa: este era o sistema da chaluká (distribuição). Os judeus deveriam representar suas comunidades, dedicar-se ao estudo da Torá e rezar em seus nomes...". Mordechai Ben-Hillel Hacohen (1856-1936), escritor, um dos fundadores de Tel-aviv e pilar do establishment sionista, descreveu com as seguintes palavras a Jerusalém judaica otomana: "Não há nenhuma outra cidade no mundo onde quase oitenta por cento dos habitantes são mantidos por auxílios de diversos tipos, e nesses auxílios eles não veem desonra, baixeza nem diminuição da alma” (apud SEGEV, 2000, p. 69). Em Desolação e Fracasso, Brenner sumariza a realidade do yishuv de Jerusalém com as seguintes palavras: 
Noventa por cento deles vivem principalmente dos donativos que eles ou alguém outro recebe por correio. Sua principal ocupação é comercializar participações em suas instituições de caridade e de mendicância. Todos esses sujeitos bem nutridos que você vê circulando por aí em suas carruagens estão recheados do sangue dos pobres e miseráveis, de cujas esmolas eles se apropriaram. Não há um único entre esses sanguessugas ignorantes vestidos de casaca que não devore as porções de dez outros junto com as suas próprias! [...] Uma cidade inteira dependente dos caprichos da filantropia! (BRENNER, 2008, p 30).

As distorções e os absurdos dessa sociedade onde só os inescrupulosos têm sucesso são o assunto central do romance. Hefetz, seu tio decrépito e suas primas desesperançadas são judeus do Leste da Europa, deslocados e infelizes, exemplos de uma mentalidade resignada e melancólica, paralisados por inseguranças que corroem a máscara de coragem e bravura propalada pelos ideais do sionismo. Eles encarnam todas as dificuldades do renascimento nacional judaico, assim como dão voz ao fantasma da regressão que paira sobre os que se lançam ao projeto dos pioneiros. É nesse sentido que, ao terminar sua consulta médica, pouco depois de sua chegada a Jerusalém vindo da colônia agrícola, Hefetz afirma: “Agora eu sou um verdadeiro hierosolimita. O que isto significa é que agora eu vou ficar por aí sem fazer nada. Ou melhor, vou ficar sentado. E com os parentes... sim, com parentes como os meus. Aí está!” (BRENNER, 2008, p. 29).

Os venenos do judaísmo diaspórico estão impregnados, também, em Yosef Hefetz, o tio de Yehezkel, que tenta ser, ao mesmo tempo, um homem religioso e um maskil, representando o esforço malogrado dos judeus da Europa para viverem ao mesmo tempo em dois mundos - o da tradição judaica e o da modernidade. Sua biblioteca, trazida da Rússia, permanece retida pelas autoridades aduaneiras otomanas porque ele não dispõe da soma necessária para pagar os tributos da importação. Resignado, ele atribui a Jerusalém "o ressecamento de sua inspiração" (BRENNER, 2008, p. 94) e volta-se com nostalgia para o mundo russo que deixou para trás. Seus conhecimentos acumulados revelam-se absolutamente inúteis na Palestina, onde se transformam num aglomerado incoerente de citações às quais ele recorre todo o tempo numa tentativa desesperada de encontrar algum sentido metafísico para suas mazelas.

A biblioteca de Yosef Hefetz sintetiza a ambição diaspórica das últimas décadas do século XIX de conciliar as fontes judaicas com a tradição da Haskalá: ali estão, ao lado do Talmude, de 
duas coleções do Midrash e de uma bíblia com todos os comentários, a História dos Judeus de Leopold Zunz, em alemão, o Tratado de Spinoza, igualmente em alemão, livros de Moses Mendelssohn e até de Schleiermacher. E, sobretudo, o Horeb de Samson Rafael Hirsch, livro do qual, segundo o narrador, Reb Yosef sentia muita falta.

O peso dessa erudição livresca encurvou a coluna de Yosef Hefetz e coincide com sua percepção de que, desde sua chegada à Palestina, sua vida se tornou uma sequência infindável de desgraças e infortúnios. "Os jovens da Palestina", diz ele, "simplesmente não sabem como honrar os mais velhos [...] aqui, uma pessoa não vale nada". "Ele foi um professor por 30 anos, por 30 anos consecutivos... mas as escolas da Palestina acharam que ele não fosse suficientemente bom”. (BRENNER 2008, p. 43).

Outro exemplo da mentalidade corrupta criada pelo sistema da chaluká no romance é Goldmann, que administra, sempre em benefício próprio, uma hospedaria mantida por contribuições da Diáspora e explora os sentimentos religiosos dos doadores para enriquecer. Hamilin, um falso médico oportunista e galanteador que Hefetz conhecera na Suíça e que vem a Jerusalém fazer carreira por meio de ligações duvidosas, é outro exemplo do caráter sombrio dos que fazem carreira no velho yishuv: o personagem tem um caso de amor com a filha de Goldmann, administrador da hospedaria onde vivem Yosef Hefetz e suas filhas, que é custeada por donativos caridosos vindos do exterior.

Se a sociedade judaica de Jerusalém é tratada com sarcasmo e ceticismo, como um aglomerado de relações incestuosas entre as instituições de caridade, os schnorers e os agentes de organizações religiosas, Hefetz é o anti-herói que sepulta o sonho da halutziut para inserir-se neste sistema corrupto e se tornar uma figura miserável que vive em meio a miseráveis.

Sua falta de virilidade é responsável pela infelicidade de suas duas primas - Miriam, jovem e atraente, em busca do amor, e Esther, a mais velha, solteirona e feia que o ajuda em sua convalescença, pois ele se apaixona pela primeira e é objeto do amor da segunda, mas não é capaz de reagir a seus sentimentos. A ligação que Hefetz estabelece com Esther é a de dois desesperados que se dão as mãos movidos pela compaixão que sentem um pelo outro, um exemplo dos desastres gerados pela insinuação do espírito da galut na própria Palestina, que acaba destruindo os objetivos do sionismo: a colonização do antigo lar nacional e o renascimento do povo judeu. 
Segundo Ruth Wisse,

\begin{abstract}
Brenner exprimiu em hebraico o vômito, a depressão e a loucura dos imigrantes judeus para a Palestina - um grupo sexualmente aleijado, culturalmente hiperdeterminado, e politicamente perseguido. Ele desenvolveu uma poética do "princípio negativo" por meio da qual somente o estilo quebrado e vacilante das neuroses poderia se tornar um veículo confiável para a recuperação nacional judaica (WISSE, 2000, p. 96).
\end{abstract}

Ideias envelhecidas, visões de mundo obsoletas, crenças que se transformaram em estruturas fossilizadas e desvitalizadas - estes são os elementos que definem a triste existência de Yosef Hefetz e de suas filhas Miriam e Esther, moças cuja esterilidade é aludida no título do livro pela palavra shekhol (que pode significar desolação, mas, também, ausência de filhos) e que, no romance, é causada não por razões biológicas, mas pela incapacidade que as duas têm de encontrar maridos adequados aos propósitos bíblicos de multiplicação.

Esta forma de vida destinada à extinção e ao esquecimento exerce, no entanto, um poder de atração irresistível sobre o malogrado Yehezkel Hefetz, que, depois de seu acidente na comunidade agrícola, regride aos padrões diaspóricos vigentes na casa de seu tio. $\mathrm{O}$ aprofundamento de sua infelicidade o leva a tal patamar de sofrimento que acaba sendo levado a uma clínica de doentes mentais, onde passará seis meses internado.

O olhar cáustico de Brenner sobre o yishuv de Jerusalém não tem por contrapartida, porém, uma visão idealizada da vida nas comunidades agrícolas, ao contrário: logo no capítulo inicial do livro, a narrativa destaca que o ambiente do kibutz é envenenado por intrigas - como as que são geradas por um personagem que é denominado simplesmente "o mestre da intriga", e que se esforça em criar discórdias entre amigos, reclamar da cozinheira e desconfiar da doença de Hefetz. A hipocrisia dos membros da comunidade, que representam de maneira pouco convincente o papel de quem só se preocupa com o interesse comum quando na realidade anseiam pela satisfação de seus desejos particulares, faz, por exemplo, com que a reunião em que se decide quem acompanhará Hefetz até Jerusalém se estenda até à uma hora da madrugada. $\mathrm{O}$ encontro só termina quando Menachem, um trabalhador contratado "que tem um fraco por estações e por passagens de trens" (BRENNER, 2008, p. 10), se oferece para acompanhar Hefetz. 
O próprio kibutz é representado, no romance, como o lugar que reúne aqueles párias e marginais que não são capazes de encontrar um lugar para eles mesmos na sociedade - e não como o criadouro de heróis proposto pela literatura dos praticantes do gênero eretz-israelense:

Em outro lugar, alguém como ele não tinha nenhuma chance. Na hospedaria dos trabalhadores, na colônia, por outro lado, cercado por ascéticos devotos do trabalho, barbudos, livrescos, lá onde todos eram um tanto excêntricos, um tanto "originais", lá e somente lá Hefetz poderia também ser um bom companheiro, ainda que ele não fosse briguento como o resto deles e não discutisse a respeito da queda de um chapéu nem tomasse partido em todas as disputas, nem se envolvesse em jogos políticos apenas por tédio e pela necessidade de dar início a uma briga... (BRENNER, 2008, p. 12).

A ida de Hefetz a Jerusalém é sua segunda "deserção" do ideal dos pioneiros. Anos antes, ele deixara a Palestina para viajar por alguns anos pela Europa, pois a colônia agrícola o fazia sentir que "estava preso a um longo corredor, que deveria levar a algum lugar" enquanto ele era obrigado a suportar o amargor e a dureza: "o ar que queimava e absorvia o suor, a hospedaria imunda, a comida venenosa e doentia, o ambiente frio e estranho; era impossível não sonhar com um lugar confortável para se viver, com uma boa refeição, sombra, um riacho fresco, bosques densos, alamedas" (BRENNER 2008, p. 13). O ambiente da colônia e as dificuldades que ele ali enfrenta eram-lhe insuportáveis:

Parecia-lhe monstruoso ter que continuar a viver assim, sem nenhum motivo, como "mão de obra agrícola judaica" sempre em busca de trabalho, monstruoso quando ele via que tinha que sair todas as manhãs para competir com uma horda de árabes desconhecidos; monstruoso ter que lutar o dia inteiro contra o capataz grosseiro; e depois voltar para a hospedaria à noite e engolir uma papa azeda e gasosa que causava maus pressentimentos ao estômago; e depois passar pelo clube dos trabalhadores para bocejar uma ou duas vezes e ler um jornal velho; e depois voltar para a hospedaria, para um sono de solteiro, mordido por insetos de todos os tipos, e depois voltar a levantar-se com a campainha do despertador e trabalhar o dia inteiro, até à noite. E o trabalho não tinha nenhum significado, e o final estava distante, embaçado, invisível, inexistente... passar um ano assim, dois anos, dez anos, uma eternidade... e nunca haveria nenhuma mudança; nenhum alívio; nenhum progresso; nenhuma esperança..." (BRENNER, 2008, p. 13). 
Assim, em sua primeira crise de melancolia, anos antes, quando Hefetz, cansado da vida monótona, insuportável, sem prazeres e sem mulheres, decidira conhecer um pouco o mundo, passou a ser desrespeitado pelos companheiros que resmungavam sobre aqueles que "fugiam do campo de batalha" e "traíam a causa nacional". Sua peregrinação pela Europa Ocidental o levou de cidade em cidade, sem descanso, contrapondo sua admiração pelo lustro e pela opulência da civilização europeia do século XX a sua miséria particular - e à miséria dos diferentes enclaves judaicos que se repetem de forma idêntica em todos os lugares. Os guetos parecem realidades ubíquas, cheios de jovens desenraizados, descontentes, cansados e indesejados, como o próprio Hefetz, que se encontram nos mesmos clubes dos trabalhadores judeus.

Por dois anos ele luta para se livrar de seus cacoetes orientais, tentando integrar-se à Europa, até mesmo mudando seu nome. Mas uma desilusão amorosa, combinada com a saudade das pessoas que ficaram na Palestina, o levará de volta à colônia, onde a vida, à distância, lhe parece cheia de significado.

O ceticismo de Brenner para com o movimento de colonização agrícola coletiva judaica antecipa-se, em quase três décadas, às críticas que seriam formuladas por escritores como $\mathrm{S}$. Yzhar, de maneira que ele pode ser considerado também como precursor dessa crítica ideológica - não obstante sua adesão à ideologia.

O pessimismo de Brenner, assim, estende-se sobre o velho yishuv e seus modelos diaspóricos tanto quanto sobre o embrião do Estado Judeu, que lhe parece de antemão condenado em razão do desvirtuamento de seus criadores. Desolação e Fracasso combina os discursos políticos, sexuais e patológicos gravados naqueles que buscam a redenção na terra de Israel, e as tragédias particulares representadas no romance são também representações de uma tragédia nacional, para a qual há necessidade de cura e salvação. Chamado de "profeta do ceticismo" por Schachar Pinsker (2011, p. 14), Brenner faz um retrato em negativo de todos os estratos da sociedade judaica - do velho yishuv de Jerusalém aos guetos do leste e do oeste da Europa até as próprias colônias agrícolas, que são o lugar da realização dos ideais do sionismo. Esse retrato desesperançado e profundamente crítico é característico de um escritor que se propõe a expor as feridas e patologias dos judeus para que eles mesmos despertem para novas formas de vida. Neste sentido, seu engajamento como autor se dá a partir das margens e do avesso da sociedade - e não por meio da exaltação de seus ideais centrais. 
Autenticidade artística e devoção às ideias do sionismo, assim, tornam-se reconciliáveis na literatura atormentada de um autor para quem o romance, mais do que um exercício de retórica sobre temas predeterminados, deveria ser, a um tempo, expressão genuína do espírito e direção da sociedade num momento específico.

O desconsolo do universo do gueto, presente na narrativa de Desolação e Fracasso na figura de Reb Haim e de sua família; os sonhos da halutziut, representados pela colônia agrícola; a tentativa de encontrar um lugar para si em meio às sociedades da Europa ocidental, cristalizada na trajetória de Hamilin tanto quanto na viagem de vários anos empreendida por Yehezkel, são modelos distintos de vida judaica e de alternativas ao esgotamento da tradição, criticados de maneira igualmente acerba por Brenner, para quem a solução para os problemas judaicos de seu tempo não estava em projetos coletivos a serem emulados em bloco, mas na transformação íntima de cada um - processo que ele desejava desencadear por meio de suas obras. Sua ênfase sobre o grotesco e o aberrante segue, antes de opções estéticas, o propósito deliberado de chocar o leitor, de levá-lo a atentar para as distorções presentes em seu quotidiano e em seu ambiente imediato. Ao por em xeque os pressupostos de uma normalidade que lhe parece inaceitável, Brenner pretende despertar da anestesia moral uma geração que vive uma época de crise, e, nesse sentido, retoma os procedimentos dos profetas bíblicos que, vendo a si mesmos como a consciência de seu tempo, castigam seus contemporâneos com suas palavras e revelam as dimensões perversas da vida social por meio de suas denúncias.

Se o choque que Brenner pretendia causar com suas obras permanece inabalado e sua leitura continua atual, após o genocídio judaico uma representação em tons tão sombrios tornouse politicamente incorreta e inaceitável. Mas, um século depois do surgimento do romance Desolação e Fracasso, numa época em que os ideais do sionismo vêm sendo profundamente questionados no âmbito acadêmico e no das realidades sociais e políticas, as invectivas de Brenner ganham nova e imprevista atualidade. O esteticismo dos modelos heroicos propalados pela ideologia do sionismo e por seus instrumentos artísticos deu lugar, na realidade israelense, ao desencantamento característico de uma sociedade neoliberal marcada pelas desigualdades, enquanto a imagem idealizada do halutz que combina as virtudes do guerreiro com a sensibilidade do homem de espírito torna-se cada vez mais corroída no âmbito de uma sociedade marcada pela violência. As críticas a uma realidade em crise por meio da literatura, porém, 
tornaram-se um instrumento perigoso, sobre o qual paira sempre o fantasma do preconceito e do auto-ódio.

\section{Referências}

ALTER, R. Hebrew and Modernity. Bloomington: University of Indiana Press, 1994. Modern Hebrew Literature. Springfield: Berman House, 1975.

BRENNER, Y. H. Breakdown and Bereavement. Londres: Toby Press, 2004.

EVEN-ZOHAR, B. Entrada do modelo do "hebreu novo" na literatura hebraica. Cadernos de Língua e Literatura Hebraica, n. 1, São Paulo: Humanitas, 1998.

HALKIN, S. Modern Hebrew Literature. Nova York: Schocken, 1950.

KLAUSNER, J. A History of Modern Hebrew Literature. Westport: Greenwood Press, 1974.

MIRON, D. From continuity to contiguity. Stanford: Stanford University Press, 2010.

PINSKER, S. Literary passports: the making of modernist Hebrew fiction in Europe. Stanford: Stanford University Press, 2011.SEGEV, T. One Palestine: complete. Nova York: Henry Holt, 2001. SHAKED, G. Modern Hebrew Fiction. Londres: Toby Press, 2000. SPICEHANDLER, E. Yosef Haim Brenner: a biography. In: BRENNER, Y. H. Out of the depths and other stories. Londres: Toby Press, 2008.

SUFIAN, S. M. Healing the land and the nation. Chicago: University of Chicago Press, 2007. WISSE, R. The Modern Jewish Canon. Nova York: The Free Press, 2000. 